\title{
O MOVIMENTO DE OCUPAÇÃO DE ESCOLAS PÚBLICAS E SUAS CONTRIBUIÇÕES PARA A EMANCIPAÇÃO HUMANA
}

\author{
Aldimara Catarina Delabona Brito Boutin \\ SIMONE dE FÁtIMA FLACH \\ Universidade Estadual de Ponta Grossa (UEPG), Ponta Grossa, \\ Paraná, Brasil
}

\begin{abstract}
REsUmo: O presente texto propõe reflexões sobre as contribuições do movimento de ocupação de escolas públicas, ocorrido nos anos de 2015 e 2016 no Brasil, para a formação dos estudantes. Para tanto, a partir de pesquisa bibliográfica, as dimensões educativas dos movimentos sociais são apresentadas tendo em vista a formação na e para a vida, evidenciando o caráter educativo das ocupações das escolas. Com base na análise da organização das ocupações, em cotejamento com a bibliografia, conclui-se que o movimento de ocupação de escolas, contribuiu para a produção de conhecimentos revolucionários imprescindíveis para a emancipação humana.
\end{abstract}

Palavras-chave: Movimento Estudantil. Ocupação de Escolas. Transformação Social. Emancipação Humana.

INTRODUÇÃO

O atual estágio do modo de produção capitalista tem demonstrado força vital para sua manutenção e desenvolvimento, por meio de um processo hegemônico que extrapola o contexto da produção e se evidencia nas normas sociais, jurídicas e políticas, determinando o modo de vida de toda a coletividade. Por isso, não é possível compreender os fatos ocorridos em determinado momento histórico sem considerar as múltiplas relações 
existentes entre estrutura e conjuntura. A esse respeito, Gramsci (2007, p. 37) alerta que "o erro em que se incorre frequentemente nas análises históricopolíticas consiste em não saber encontrar a justa relação entre o que é orgânico e o que é ocasional".

Tendo clara essa questão, o presente texto tem a pretensão de analisar as forças que atuam no contexto econômico, social e político brasileiro e sua relação com o movimento estudantil secundarista (em específico os movimentos de ocupação de escolas em diferentes regiões do país, ocorridos nos anos de 2015 e 2016), e, ainda, evidenciar o caráter educativo do movimento estudantil para a formação da juventude com vistas à emancipação humana, em uma perspectiva revolucionária ou transformadora da realidade.

Nessa perspectiva, é importante destacar que na última década do século XX o governo brasileiro abriu as portas alfandegárias para a produção internacional, não medindo esforços para a reorganização política, jurídica e administrativa que oferecesse condições à entrada e especulação das grandes corporações e conglomerados financeiros internacionais. Essa estratégia do governo brasileiro deu sustentabilidade para o alastramento dos ideais liberais, revisitados sob a designação de neoliberalismo, e fundamentou a reforma da administração pública, que visava a um ajuste fiscal e por meio de reorganização legal que objetivava oferecer o lastro normativo para a efetivação de reformas (financeiras, comerciais, trabalhistas, etc), além de reduzir e limitar as funções estatais, em especial aquelas relativas aos direitos sociais.

Segundo Cardoso (2006, p. 15),

Mudar o Estado significa, antes de tudo, abandonar visões do passado de um Estado assistencialista e paternalista, de um Estado que, por força de circunstâncias, concentrava-se em larga medida na ação direta para a produção de bens e serviços. Hoje, todos sabemos que a produção de bens e serviços pode e deve ser transferida à sociedade, à iniciativa privada, com grande eficiência e com menor custo para o consumidor.

Essa lógica, embora criticada por partidos de esquerda, sofreu leve refluxo, mas não se findou com a efetivação de governos vinculados ao Partido dos Trabalhadores. Contrariamente aos discursos e defesas realizados antes de assumirem o poder, os governos petistas (2003 - 2016) optaram, para garantir a governabilidade, pela manutenção da lógica capitalista que norteou as ações do governo anterior, sem mudar radicalmente a estrutura econômica, social e política brasileira. Segundo obra organizada por Singer e Loureiro (2016), os governos petistas não foram capazes de enfrentar minimamente o capital, 
acentuando o apoio às indústrias por meio da adequação do aparato legal; não realizaram a tão propalada reforma agrária e urbana, culminando com a concentração de terras e fortalecimento do agronegócio em detrimento dos pequenos produtores; além de acreditar na mágica de dar aos pobres sem tirar dos ricos. Essas ações demonstram como os ideais capitalistas têm força e orientam as escolhas de governos vinculados a diferentes concepções ideológicas.

No setor educacional o enfrentamento das dificuldades para a garantia do direito à educação tem se curvado à mesma lógica advinda do setor produtivo. Nesse sentido, a preocupação com os índices de acesso, permanência e formação para o mercado de trabalho tem orientado fortemente as políticas educacionais brasileiras, refletindo nas ações dos estados e municípios, sob a justificativa de eficácia e eficiência do sistema educacional.

As contradições se evidenciam em inúmeros projetos e propostas educacionais em curso no Brasil: ao mesmo tempo em que se prolonga o tempo de permanência dos alunos na escola, não há contratação de profissionais qualificados e adequação estrutural (espaços físicos, reorganização curricular e pedagógica) para esse atendimento; o acesso ao ensino superior se amplia, sem a devida proporção de investimento nas universidades públicas, mas com repasse de recursos públicos para as instituições privadas; as exigências para a melhoria dos índices educacionais convivem com a contratação precária de professores, falta de recursos materiais e financeiros, dentre outros aspectos.

Tais situações vêm sendo alvo de estudos e denúncias realizadas por pesquisadores de todo o país e têm mobilizado diferentes setores da sociedade em defesa da educação pública e de qualidade. Nos últimos anos, os estudantes têm demonstrado capacidade de organização e luta em prol de direitos conquistados, os quais têm sido paulatinamente desconsiderados ou reduzidos sob a justificativa de redução de custos ou eficiência do sistema educativo. Esse contexto, embora conjuntural, evidencia a ausência de políticas de Estado voltadas à educação, em detrimento das políticas de governo, tão criticadas pelo seu caráter reformista.

Em 2015, o governo do estado de São Paulo propôs uma reestruturação da organização do ensino, prevendo o remanejamento de mais de 310 mil alunos e 74 mil professores e o consequente fechamento de 200 unidades escolares, segundo Campos, Medeiros e Ribeiro (2016). Em face da proposta, os estudantes organizaram diversos protestos e atos públicos em pelo menos 60 cidades paulistas. Os mesmos autores, baseando-se em entrevista realizada com jovens do movimento, indicam que as manifestações 
foram inspiradas na "Revolta dos Pinguins"1 ocorrida no Chile em 2006, quando os estudantes adotaram, como forma de pressão por suas demandas, a estratégia de ocupações de prédios escolares. No mesmo ano, no estado do Paraná, os estudantes foram às ruas em protesto contra a decisão do governador de fechar mais de 100 escolas estaduais, havendo, em razão dos protestos e da falta de acordo, o recuo do governo relativo à medida.

Em 2016, diante da iniciativa do governo federal em propor uma Emenda Constitucional ${ }^{2}$ que congela os investimentos públicos (dentre os quais, a educação) por um período de 20 anos; e a publicação da Medida Provisória no 746/2016³, alterando a Lei no 9394/96 em relação à oferta do Ensino Médio, os estudantes paranaenses novamente se mobilizaram contra tais medidas, ocupando instituições de ensino em todo o estado.

O movimento de ocupações tomou projeção nacional. Segundo os dados do movimento Ocupa Paraná, ${ }^{4}$ foram ocupadas cerca de 850 escolas, 14 universidades e 3 núcleos regionais de educação. Em nível nacional a União Brasileira dos Estudantes Secundaristas (UBES) ${ }^{5}$, contabilizou um total de 1.197 escolas ocupadas (ZINET, 2016).

Os secundaristas envolvidos no movimento de ocupações das escolas em 2016 enfrentaram duras críticas de alguns setores da sociedade civil, dentre os quais se destaca: a mídia e o Movimento Brasil Livre ${ }^{6}(\mathrm{MBL}$ ) que assumiu no estado a insígnia de "Desocupa Paraná", os quais realizaram pressão social e ideológica contra as ocupações, reivindicando a desocupação imediata dos espaços escolares (ZINET, 2016).

As ocupações de escolas pelos estudantes evidenciaram a correlação de forças existentes no seio da sociedade, e, demonstraram que os jovens se constituem em força ativa visto que "conseguiram mobilizar milhares de estudantes em processos democráticos reais" (ORTELLADO, 2016, p.16). Por meio de sua atividade prática, os estudantes mostraram que não estão alheios às questões políticas do país e que são capazes de realizar ampla mobilização para a luta em prol de uma educação pública e de qualidade. Nessa perspectiva, o movimento de ocupações das escolas públicas deixou como herança diferentes aprendizados que não estão presentes nos currículos formais da escola.

A partir das dimensões educativas apresentadas nos movimentos sociais, propostas por Gohn (2012), pretendemos refletir acerca das dimensões educativas vivenciadas no movimento de ocupação das escolas públicas no Brasil e de que forma tais vivências podem colaborar para o processo formativo dos estudantes. 
$\mathrm{O}$ artigo divide-se em duas partes. Na primeira discorre-se sobre as três dimensões educativas dos movimentos sociais, conforme apresentadas por Gohn (2012), quais sejam: política, cultural e espacial. Na segunda parte aborda-se sobre o movimento das ocupações dos estudantes secundaristas no ano de 2015 e 2016 e o caráter educativo das atividades vividas pelos secundaristas nos espaços ocupados. Depois, conclui-se que o movimento estudantil, materializado nas ocupações de escolas públicas, contribuiu de forma incontestável, para a ampliação da consciência sobre as contradições da realidade vivida, produzindo "conhecimentos revolucionários" (TONET, 2014, p. 16) comprometidos com a transformação social.

\section{RELAÇÕES ENTRE MOVIMENTO ESTUDANTIL E EDUCAÇÃO NA E PARA A VIDA}

"Só na luta as tarefas da luta se tornam claras. Organização, esclarecimento e luta não são momentos separados, mas diferentes aspectos do mesmo processo. (LUXEMBURG, 1991, p. 43)".

Precisamos compreender que as relações sociais se fazem no processo de correlação de forças que visam à manutenção ou transformação da realidade. Por isso, são sempre políticas e evidenciam o antagonismo de classes que fundamentam a sociedade capitalista. A busca pela transformação ou manutenção de uma realidade social, econômica ou política é o fundamento que move os embates no interior da sociedade. Nesse sentido, os movimentos sociais podem ser conceituados como formas de expressão em que os sujeitos exprimem suas demandas e apontam caminhos possíveis para o seu alcance. Para tanto, os indivíduos se valem de diferentes estratégias como: manifestações, passeatas, marchas, concentrações, ocupações de espaços públicos, entre outras (GOHN, 2011).

Atualmente, o movimento estudantil vem representando uma resistência importante à ideologia dominante. Tanto a ocupação de escolas paulistas em 2015, quanto as ocupações de 2016 em diversos estados colocou em evidência o comprometimento dos jovens na manutenção e ampliação de direitos historicamente adquiridos. A esse respeito, e revisitando acontecimentos históricos, Gohn (2016) destaca que,

O movimento dos Estudantes- ME, especialmente os do ensino médio e universitário, merece um destaque maior porque ele sempre esteve presente em momentos cruciais da história política do país. Das ações dos estudantes de Direito na fase do Brasil Império, passando pelas lutas estudantis dos anos 60, pelas Diretas Já de 1984, pelos Caras Pintada de 1992, até a UNE atual, e as novas formas de ação, com ocupações em órgãos administrativos da 
universidade, ou as ocupações de escolas por estudantes do ensino médio, os estudantes são atores políticos relevantes no Brasil. (GOHN, 2016, p. 2)

Historicamente é possível afirmar que a ação dos estudantes contribuiu para alterações sociais importantes no contexto brasileiro. Embora não exista consenso em relação ao período ${ }^{7}$ histórico que se iniciou o movimento estudantil brasileiro, autores como Poermer (1979), Mendes Jr. (1982), Fávero (1995), Valle (1999), Araújo (2007) e Sanfelice (2008) discorreram em suas obras sobre a atuação dos estudantes brasileiros desde o período do Império até o contexto da Ditadura Militar de 1964. $\mathrm{Na}$ atualidade, o movimento secundarista tem sido objeto de análise de diferentes pesquisadores, dentre os quais ressaltamos Campos, Medeiros e Ribeiro (2016); Catini, Mello (2016); Santos (2016).

O movimento estudantil está atrelado aos movimentos sociais mais amplos e se inserem na luta contra a hegemonia vigente em diferentes períodos históricos, caracterizando-se como um processo social, político e educativo, que forma no processo de luta vivida. Nesse sentido, o movimento estudantil assume caráter educativo, contribuindo para a tomada de consciência sobre a importância da participação, sobre os direitos dos cidadãos e ainda auxilia na leitura crítica da realidade em que os indivíduos se inserem. (PARREIRA; FILHO, 2010).

É nesse sentido que a educação não formal, aquela realizada além dos espaços e currículos escolares, pode ser compreendida como uma práxis social8, e uma "práxis intencional" a qual auxilia para a "produção de uma nova realidade política, econômica ou propriamente social" (VÁZQUEZ, 2011, p. 337).

Segundo Gohn (2011, p. 333), a educação se realiza em espaços que ultrapassam os muros da escola, ou seja, a participação em movimentos sociais promove a aquisição de "aprendizagens e produção de saberes". Ainda para a autora, a possibilidade educativa dos movimentos sociais se expressa por meio de três dimensões: a dimensão da organização política, a dimensão da cultura política e a dimensão espacial temporal (GOHN, 2012).

$\mathrm{Na}$ "dimensão da organização política" amplia-se a conscientização tanto sobre os direitos adquiridos como sobre os direitos inseridos na pauta das lutas. Essa conscientização se dá por meio de um longo processo e sua efetivação é facilitada pela parceria com diferentes segmentos da sociedade civil como, entidades jurídicas, políticas ou religiosas. (GOHN, 2012)

A construção da cidadania coletiva se realiza quando identificados os interesses opostos, parte-se para a elaboração de estratégias de formulação de demandas e táticas de enfrentamento dos oponentes. Este momento 
demarca uma ruptura com a postura tradicional de mandatários de bens de consumo coletivo: não se espera o cumprimento de promessas, organizam-se táticas e estratégias para a obtenção do bem por ser um direito social. (GOHN. 2012, p. 22)

Nessa perspectiva, a aquisição de aprendizados se efetiva por meio da consciência sobre as contradições que permeiam a realidade social, na busca pela ampliação dos direitos e ainda pela organização de estratégias de lutas. Na prática do movimento estudantil universitário e secundarista, no contexto da Ditadura Militar de 1964, é possível evidenciar a referida dimensão, visto que os jovens, conscientes da importância da organização comprometida atuaram ao lado de diferentes setores da sociedade civil ${ }^{9}$, unificando os objetivos em apenas uma luta, o que contribuiu para o fortalecimento do movimento e para a alteração dos encaminhamentos políticos adotados até então. (VALLE, 1999).

A segunda dimensão se refere à ampliação da cultura política. Para Gohn (2012, p. 23), a "prática cotidiana nos movimentos sociais" possibilita o conhecimento de experiências do passado e fornece "elementos para a leitura do presente" (p. 23). Dessa forma, por meio da aquisição da cultura política aprende-se:

[...] decodificar o porquê das restrições e proibições. Aprende-se a acreditar no poder da fala e das ideias, quando expressas em lugares e ocasiões adequadas. [...] Aprende-se a criar códigos específicos para solidificar as mensagens e bandeiras de lutas, tais como músicas e folhetins. Aprende-se a elaborar discursos e práticas segundo cenários vivenciados. E aprende-se, sobretudo a não abrir mão de princípios que balizam determinados interesses como seus. (GOHN, 2012, p. 23)

Com base no exposto, percebe-se que a aquisição da cultura política facilita a compreensão das contradições que permearam e ainda permeiam os discursos e concepções hegemônicas. De posse de tal entendimento, há maior facilidade para a elaboração de diferentes táticas de enfrentamento e estratégias de lutas nos movimentos sociais, como ocorreu no contexto da Ditadura Militar de 1964 em diferentes episódios em que os estudantes elaboraram novas estratégias de luta ${ }^{10}$, em busca de maior eficiência no confronto com os militares. (ARAÚJO, 2007)

A dimensão espacial temporal igualmente contribui para a aquisição de saberes que não integram os currículos escolares. A utilização de espaços públicos além de ser um recurso importante para o desenvolvimento das atividades dos movimentos, também propicia "o desenvolvimento da consciência de cidadania no sentido de uso da coisa pública" (GOHN, 2012, 
p. 25). Essa dimensão apresentou-se nas lutas do movimento estudantil no período da Ditadura Militar de 1964, visto que os jovens se valeram do uso de diferentes espaços públicos para a realização das atividades.

As dimensões educativas expressas na prática dos movimentos sociais, elencadas por Gohn (2012), podem ser localizadas não apenas no ativismo do movimento estudantil no contexto da Ditadura Militar de 1964, mas também no movimento estudantil da atualidade. As recentes mobilizações dos jovens secundaristas organizadas em decorrência do descontentamento com as políticas para a educação propostas pelo Estado evidenciam seu comprometimento com a"participação, cidadania e o sentido político da educação" (GOHN, 2016, p. 01).

Nesse sentido, o movimento estudantil pode ser apontado como espaço privilegiado para o processo formativo dos jovens, tendo como pressupostos a compreensão da realidade e de suas contradições, oferecendo possibilidades para uma tomada de decisão a respeito da manutenção ou transformação da realidade. O processo educativo que ocorre na vivência do movimento estudantil se torna coletivo e desenvolve compromissos sociais, políticos e econômicos, podendo ser caracterizado como uma verdadeira formação humana, que tem o compromisso com toda a coletividade.

\title{
O CARÁTER FORMATIVO DO MOVIMENTO ESTUDANTIL DA ATUALIDADE
}

\begin{abstract}
Além da opressão do governo, as pessoas com quem deveríamos contar indo contra nossos direitos? Às pessoas que querem nossa desistência, só um recado: NÃO TEM ARREGO! (Página de uma ocupação na zona leste de São Paulo, In: CAMPOS; MEDEIROS; RIBEIRO, 2016, p. 185).
\end{abstract}

No estado de São Paulo teve início, em 2015, um movimento em defesa da escola pública e contra a reorganização escolar proposta pelo governo estadual. Durante o processo de ocupações cerca de duzentas escolas paulistas foram ocupadas. Em 2016, os estudantes de vários estados brasileiros se mobilizaram contra as propostas do governo federal de reajuste fiscal e reforma do Ensino Médio. Destaca-se nesse contexto, além da ocupação de escolas paulistas e mineiras, as ocupações de escolas paranaenses que atingiram 850 instituições e interferiram na vida social em quase todos os 399 municípios do estado.

Para Gimenes (2016) o movimento de ocupações pode ser compreendido como um dos caminhos para que as classes subalternas explicitem o seu descontentamento em relação a desigualdade econômica, social e política. A autora explicita que"o levante estudantil secundarista pode 
ser considerado o movimento social de maior expressão político-simbólica no Brasil de hoje" (p. 5). Ainda, a mesma autora enfatiza que o movimento de ocupações das escolas públicas "produz aprendizagens para aqueles que dele participam" (p. 7).

Os aprendizados efetivados por meio da participação em movimento sociais promovem experiências que ultrapassam os currículos escolares, pois nascem da conscientização dos sujeitos sobre a urgência em superar o capitalismo e as desigualdades nele presentes.

É nesse contexto que, para Zinet (2016, p. 2), os jovens presentes no movimento de ocupação mostraram que é possível um modelo de educação que "ultrapasse as paredes da sala de aula e os muros da escola", pois o "aprendizado não se limita ao acesso aos conteúdos" (p.2). Com base em tal perspectiva o autor elenca algumas atividades desenvolvidas pelos estudantes durante o episódio das ocupações e as contribuições das mesmas para a aquisição se saberes extracurriculares, conforme se segue:

CUIDADO COM A ESCOLA: Os alunos realizaram pequenas reformas nas escolas ocupadas como pinturas, trabalhos de jardinagem, limpeza de quadras, conserto de materiais de uso coletivo, entre outros. Esta experiência contribuiu para o aprendizado em relação ao cuidado com o espaço físico e com o patrimônio escolar.

1. PROTAGONISMO: Os secundaristas organizaram oficinas e atividades culturais. Houve a sistematização das atividades por meio de comissões responsáveis por assuntos como: alimentação, limpeza, entrevistas, programação cultural, entre outros. Esta experiência evidenciou tanto o interesse dos jovens em aprendizados diversificados, como a organização do movimento estudantil secundarista.

2. AUTOGESTÃO: O movimento estudantil se organizou por meio de comissões ${ }^{11}$ responsáveis pela realização das atividades. Essas comissões foram eleitas por meio de um processo democrático com a participação de todos os jovens inseridos no processo. Essa experiência explicitou na prática a valorização da participação democrática, visto que os jovens desconstruíram modelos hierarquizados de gestão.

3. CURRÍCULO INTEGRADO: A diversificação curricular fez parte das oficinas, palestras e atividades culturais proporcionadas pelo movimento estudantil secundarista. Essas atividades contemplaram diferentes áreas do conhecimento e 
proporcionaram a aquisição de aprendizados por meio da utilização de diferentes ferramentas e técnicas de ensino.

4. CUIDADO COM A ALIMENTAÇÃO: Os estudantes arrecadaram alimentos por meio de doações efetuadas pela comunidade, rejeitaram qualquer ajuda de partidos políticos e foram os próprios jovens quem se organizaram para cozinhar, lavar a louça e elaborar os cardápios.

No mesmo sentido, Campos, Medeiros e Ribeiro 2016, p. 149, relatando sobre o movimento de ocupação de escolas paulistas no ano de 2015, concluem que "algumas escolas ocupadas se transformaram quase em centros culturais". Os autores ainda citam algumas atividades desenvolvidas como aulas, oficinas, debates, exercícios físicos, aulas de dança, música, artes, artesanato e cinema entre outras, as quais colaboram para uma formação ampliada dos jovens.

Com base nas experiências vivenciadas pelos estudantes durante 0 processo de ocupações e as reflexões de diferentes pesquisadores torna-se possível compreender que o movimento estudantil secundarista possibilitou o contato dos jovens com um modelo de educação diferente daquele vivido na escola formal. Nesse sentido, podemos localizar as dimensões educativas de Gohn (2012) nas experiências e atividades efetivadas nas escolas ocupadas.

A "dimensão da organização política" se expressou na clareza sobre as motivações da luta dos estudantes. Foi possível evidenciar tanto nas ocupações paulistas de 2015 quanto nas ocupações a nível nacional de 2016, a união dos jovens em torno da luta por uma educação pública de qualidade. Segundo Ortellado (2016), outro aspecto que coloca em evidencia a dimensão da organização política foi o apoio dos diferentes setores da sociedade, como intelectuais e artistas que realizaram shows e doaram aulas durante a ocupação das escolas.

A dimensão da cultura política se expressou na organização das estratégias de lutas, as quais para Ortellado (2016) podem ser consideradas como inovadoras, visto que o movimento dos estudantes não se limitou à ocupação das escolas, os jovens organizaram passeatas, fizeram abaixo assinados, realizaram aulas públicas, bloquearam ruas e avenidas. Dessa forma, o movimento estudantil secundarista "soube utilizar um espectro tão amplo de táticas e se metamorfosear em tão curo espaço de tempo" (ORTELLADO, 2016, p. 14)

Por fim, a dimensão e espacial temporal foi o aspecto que norteou o processo de ocupações. A utilização de espaços escolares foi um recurso importante para o movimento estudantil secundarista e facilitou o desenvolvimento das diferentes atividades que deram sustentação ao 
movimento. Aqui é importante destacar o uso consciente dos espaços públicos por parte dos jovens, posto que eles promoveram diversas melhorias no interior das escolas em que ocuparam.

Destaca-se a contribuição de Ortellado $(2016$, p. 13) em relação ao processo de ocupações das escolas públicas:

Os secundaristas romperam o isolamento individualista do cotidiano escolar e criaram uma nova sociabilidade no processo de luta: uma sociabilidade baseada na corresponsabilidade, na horizontalidade dos processos decisórios e no cuidado com o patrimônio público. Essas novas relações são o que uma tradição autonomista chama de política pré-figurativa, a capacidade de forjar, no próprio processo de lutas, as formas sociais a que se aspira, fazendo convergir meios e fins. A sociabilidade horizontal, corresponsável e baseada na proteção do patrimônio público é, ao mesmo tempo, objetivo da luta e da criação imediata, uma espécie de antecipação performativa daquilo que se busca. (p.13)

As experiências vividas nas escolas ocupadas contribuíram para a efetivação de diferentes aprendizados, facilitou a aquisição de diferentes saberes e igualmente propiciou o acesso a diferentes culturas, além de fornecer a possibilidade de reflexão e debate a respeito do contexto político, social e educacional. Enfim, o movimento das ocupações cooperou para a aquisição de saberes que ultrapassam os currículos escolares, conforme defendeu Gohn (2011) na argumentação sobre as contribuições dos movimentos sociais.

Para Arroyo (2003) é possível captar nos movimentos sociais diferenciadas maneiras de conhecer a realidade social. $O$ autor explicita que neles são expostas questões agrárias, problemas urbanos, educação, saúde, entre outros. Ainda oferecem "modos de conhecer a lógica social" (ARROYO, 2003, p. 43) que ultrapassam as matrizes curriculares da educação formal. Dessa forma, para o autor citado, os movimentos sociais:

[...] nos advertem que o conhecimento socialmente construído é muito mais diversificado do que as áreas curriculares pensam. Eles nos colocam questões complexas no campo da sociologia do conhecimento. No campo de construção e apreensão do conhecimento. (ARROYO, 2003, p. 43)

Isto significa que a participação em movimentos sociais rompe com a lógica formal de acesso aos conhecimentos, colocando em xeque as estruturas dominantes. Mészaros (2005) igualmente contribui com a reflexão ao discorrer que a educação pode se realizar fora de instituições formais de ensino. Esse autor reconhece que o papel desempenhado pela educação 
formal nos últimos anos serviu para a expansão do capital, por isso a educação não formal surge como um meio de transformação social.

No discurso proferido no Congresso das Juventudes Comunistas, na Rússia, Lênin (2015) reconheceu o potencial da juventude para um processo de transformação social. Para ele, a geração de jovens militantes, embora tenham sido educados no sistema capitalista, pode "destruir as bases da velha vida capitalista baseada na exploração" (LÊNIN, 2015, p. 11). Lênin (2015) reconheceu a importância da atuação dos jovens por meio de organizações juvenis e discorreu sobre as tarefas das Uniões das Juventudes:

[...]. A tarefa da União das Juventudes consiste em organizar sua atividade prática de modo que ao estudar, ao organizar-se, ao se reunir, ao lutar tal juventude realize sua educação de comunistas e de todos os que a reconhecem como dirigente. Toda educação, toda a instrução e todo ensino da juventude contemporânea devem trazer-Ihe a moral comunista. (LÊNIN, 2015, p. 26)

O que LÊNIN (2015) compreendeu como moral comunista se refere a conscientização sobre a importância da atuação prática. Para ele a aquisição dos conhecimentos historicamente acumulados pela humanidade irá facilitar a moral comunista e fornecer as bases para que os sujeitos se libertem "da exploração do trabalho" (LÊNIN, 2015, p. 33).

$\mathrm{O}$ ato de desvelar as contradições da sociedade é essencial para o processo de transformação social. É nesse sentido que se ressalta a urgência do comprometimento dos sujeitos para a transformação da sociedade. Os estudantes que participaram do movimento das ocupações demonstraram por meio da atuação prática o quão importante e urgente é essa luta. E tendo aprendido muito durante o processo de ocupações, os estudantes também registram importantes ensinamentos para toda a sociedade: que é possível outra forma de educação em outra escola, que a luta precisa ser vivida para se constituir em instrumento de aprendizagem, que as denúncias precisam ser feitas e, por fim, que a busca por outro modo de produção e de vida nunca foi tão atual.

\section{CONSIDERAÇÕES FINAIS}

O capitalismo como modo de produção voltado para a expansão e para a acumulação, conforme indicou Mészáros (2002), utiliza-se da educação como um dos recursos para garantir a sua hegemonia. No entanto, é importante destacar que apontar os limites da educação não significa desconsiderar as potencialidades nela latentes, pois a mesma pode se converter em um instrumento para romper com a ordem vigente. 
Nesse sentido, é de grande validade a argumentação de Tonet (2014, p. 14) quando discorre que o acesso aos conhecimentos escolares "não é condição suficiente para embasar a luta pela sua emancipação", pois se assim fosse "alguns dos países mais desenvolvidos teria uma consciência e uma atuação revolucionárias". O autor ainda enriquece a reflexão expondo que atualmente a formação para a emancipação humana não é efetivada de forma eficiente no modelo de educação institucionalizada.

É dessa forma que uma proposta de educação que pretenda romper com a lógica vigente se faz urgente no atual contexto e é nesse sentido que os movimentos sociais surgem como alternativas que além de contribuírem para a o atendimento das demandas coletivas também são meios que agregam em si potencialidades educativas. Com base nessa perspectiva e de posse do entendimento de que o pressuposto fundamental para uma formação que contribua para a emancipação humana é a aquisição da consciência sobre as contradições que permeiam o funcionamento e a estrutura da sociedade capitalista, ressaltamos as contribuições do movimento de ocupação das escolas públicas.

Assim, as atividades desenvolvidas durante o processo de ocupação de escolas públicas em diferentes estados brasileiros contribuíram para o debate acerca de questões fundamentais que auxiliam no processo de consciência individual e coletiva, tais como: os efeitos nefastos da divisão hierárquica do trabalho que contribui para o distanciamento entre as classes sociais, colocando riqueza e miséria em polos opostos; o papel do Estado na manutenção e desenvolvimento do capitalismo, principalmente a respeito das ações empreendidas para a precarização das escolas e fragmentação (quando não eliminação) de conhecimentos necessários para a compreensão, crítica e superação da realidade, dentre outras. Enfim, as ocupações de escolas contribuíram, de forma incontestável, para a ampliação da consciência sobre as contradições da realidade o sujeito está inserido, podendo ser caracterizadas como etapa do processo de emancipação, pois conforme Marx indicou "temos de emancipar a nós mesmos antes de emancipar os outros" (MARX, 2010, p. 34).

O movimento estudantil, materializado nas ocupações, contribuiu para o processo de emancipação individual de cada sujeito que nele esteve inserido, pois a atuação discente propiciou tanto o entendimento de que os secundaristas precisavam se emancipar das relações de subordinação que vivenciavam em seu cotidiano escolar como também produziu aprendizados coletivos muito importantes para um processo de emancipação humana.

Além disso, a atuação estudantil contribuiu para denunciar os problemas da educação pública envolvendo toda a sociedade no debate; mostrou a precariedade das escolas públicas, seja em relação a sua estrutura física ou de recursos humanos para o desenvolvimento de uma educação de qualidade; colocou em xeque o alcance, validade e eficiência das políticas 
educacionais em andamento, e por fim possibilitou a reflexão coletiva sobre a realidade econômica e política brasileira.

Todos esses aprendizados desenvolvidos durante o processo de ocupação das escolas públicas se inserem como pressupostos indispensáveis para uma formação humana. No entanto, a contribuição maior do movimento estudantil foi a percepção social de que os jovens são sujeitos históricos capazes de transformações sociais. Para os jovens envolvidos nas ocupações esta percepção se vincula aos conhecimentos adquiridos na luta, na prática social, por isso podem ser denominados, conforme indicados por Tonet (2014, p. 16) de "conhecimentos revolucionários", visto que estão articulados a um projeto de transformação social.

\section{THE MOVEMENT THAT OCCUPIED THE PUBLIC SCHOOLS AND ITS CONTRIBUTION FOR HUMAN EMANCIPATION}

AвSTRACT: This text proposes the reflections on the contributions of the movement of occupation of public schools, occurred in the years of 2015 and 2016 in Brazil, for the formation of the students. For that, based on bibliographical research, the educational dimensions of the social movements are presented with a view to training in and for life, evidencing the educational character of the occupations of schools. Based on the analysis of the organization of occupations, in comparison with the bibliography, it is possible to conclude that the movement of occupation of schools contributed to the production of revolutionary knowledge essential for human emancipation.

KEYWORDS: Student movement. School occupation. Social transformation. Human emancipation.

\section{EL MOVIMIENTO DE OCUPACIÓN DE ESCUELAS PÚBLICASY SUS CONTRIBUCIONES PARA LA EMANCIPACIÓN HUMANA}

RESUMEN: Este texto propone reflexiones sobre las contribuciones del movimiento de ocupación de escuelas públicas, ocurrido en 2015 y 2016 en Brasil, para la formación de los estudiantes. Por lo tanto, a partir de una investigación documental, se presenta la dimensión educativa de los movimientos sociales con miras a una formación para la vida, destacando el carácter educativo de las ocupaciones de las escuelas. Basándose en el análisis de la organización de las ocupaciones en colación con la literatura específica, se concluye que el movimiento de ocupación de escuelas, 
contribuyó para la producción de conocimientos revolucionarios esenciales para la emancipación humana.

Palabras clave: Movimiento Estudiantil. Ocupación de escuelas. Transformación social. Emancipación Humana.

\section{NOTAS}

1 A Revolta dos Pinguins ocorreu no ano de 2006 no Chile. A primeira pauta de reivindicações dos estudantes que participaram dessa revolta incluía a gratuidade do exame de seleção para acesso ao ensino superior, passe livre, melhoria na merenda escolar e reformas nos prédios escolares, mais tarde a pauta dos estudantes passou a incluir a revogação da Lei Orgânica Constitucional do Ensino (LOCE) a qual é herança do governo de Pinochet (ZIBAS, 2008).

20 Governo Federal apresentou o Projeto de Emenda à Constituição (PEC) n 241/ 2016 (Câmara dos Deputados e PEC n 55/2016 no Senado Federal), visando alterar o Ato das Disposições Transitórias da Carta Magna e instituir um novo regime fiscal. Após ter sido aprovada na Câmara dos Deputados e no Senado Federal instituiu-se a Emenda Constitucional no 95/2016.

3 Destacamos os seguintes pontos da Medida Provisória no 746/2016, foco de insatisfação e questionamento dos estudantes e profissionais da educação: a ampliação da carga horária anual de 800 para 1400 horas (sem investimento necessário para ampliação de espaços e contratação de profissionais); a não obrigatoriedade das disciplinas de Artes, Educação Física, Sociologia e Filosofia; e, ainda, a previsão de atuação de profissionais não habilitados, os chamados "profissionais com notório saber". 4 OCUPA PARANÁ.ORG. 2016. Disponível em: <http://ocupaparana.org/>. Acesso em: 28. fev. 2016.

5 Disponível em: <http://ubes.org.br/2016/ubes-divulga-lista-de-escolas-ocupadas-e-pautas-das-mobilizacoes/>. Acesso em: 28. fev. 2016.

60 Movimento Brasil Livre (MBL) pode ser definido como uma organização não governamental. Foi instituído em 2014, sendo central no “Movimento vem pra Rua”, que exerceu pressão para a instauração do Processo de Impeachment de Dilma Rousseff e, consequentemente, ofereceu apoio ao governo de Michel Temer.

7 Poermer (1979) considera como o episódio que marcou o início do movimento estudantil brasileiro foi uma mobilização organizada no ano de 1710 por cerca de 400 estudantes oriundos de colégios religiosos, cujo objetivo era a expulsão de um grupo de corsários franceses que agiram sob a liderança do Conde Dulclerc para saquear a cidade do Rio de Janeiro. Para Mendes JR (1982), o referido episódio foi apenas uma 
ação instintiva, não foi planejado e organizado e por isso não pode ser considerado como o evento que marcou o início da participação política dos estudantes brasileiros.

8 Para Vázquez (2011), o homem historicamente veio transformando as realidades sociais em que esteve inserido. Dessa forma, é possível afirmar que "o homem é um ser prático"(VÁZQUEZ, 2011, p. 338) que "ao mesmo tempo em que transforma produz a realidade humana", a "história humana nada mais é do que a história de sua práxis" (VÁZQUEZ, 2011, p. 338), a "história humana nada mais é do que a história de sua práxis" (p. 338), visto que os homens por meio de sua atividade prática tanto criaram condições para o aparecimento de sistemas sociais como o escravismo, o feudalismo e o capitalismo e com a sua "práxis social, protestos, rebeliões ou revoluções" contribuíram a superação de diferentes relações sociais.

9 Diferentes setores da sociedade civil atuaram juntamente aos estudantes em protestos e lutas contra a Ditadura Militar de 1964, dentre esses podemos citar: a Igreja Católica, que atuou juntamente com as Comunidades Eclesiais de Base e das Pastorais [...], a Ordem dos Advogados do Brasil (OAB), a Associação Brasileira de Imprensa (ABI). Ainda merecem destaque a atuação das associações de moradores os movimentos de mulheres, o movimento negro, o movimento gay, a imprensa alternativa com "jornais de crítica e discussão política, alguns satíricos, como o Pasquim" (ARAÚJO, 2007, p. 213).

10 Araújo (2007) discorre que o movimento estudantil na luta contra a Ditadura Militar de 1964, adotou diferentes estratégias. A autora relata que os estudantes após sofrerem com a violência dos militares passaram evitar o confronto com a polícia, a ordem era fazer manifestações pacíficas. As passeatas então foram substituídas por corridas, e manifestações-relâmpagos, "o intuito era mostrar que violenta e truculenta era a ação policial, não as manifestações estudantis" (ARAÚJO, 2007, p. 221).

11 Campos, Medeiros e Ribeiro (2016) citam o Manual “O mal-educado", o qual expõe sobre as comissões que são essenciais durante um processo de ocupação. De acordo com o referido manual as comissões indispensáveis seriam: alimentação, segurança, imprensa, informação, limpeza e relações externas.

\section{REFERÊNCIAS}

ARAÚJO, M, P. Memórias estudantis: da fundação da UNE aos nossos dias. Rio de Janeiro: Ed. Relume Damara, 2007.

ARROYO, M, G. Pedagogias em movimento: o que temos a aprender com os movimentos sociais? Currículo sem fronteiras, v.3, n.1, p. 29-49 jan./jun. 2003.

CAMPOS, A, M; J, MEDEIROS; RIBEIRO, M, M. Escolas de Luta. São Paulo: Editora Veneta, 2016.

CARDOSO, F. H. Reforma do Estado. In: BRESSER-PEREIRA, L. C.; SPINK, P. (Org.). Reforma do Estado e administração pública gerencial. 7. ed. Rio de Janeiro: FGV, 2006. p. 15-20. 
CATINI, C, R; MELLO, G, M, C. Escolas de luta, educação política. Educação e Sociedade, Campinas, v. 37, n. 137, p. 1.177-1.202, out./dez. 2016.

FÁVERO, M. L. A UNE em tempos de autoritarismo. Rio de Janeiro: Editora UFRJ, 1995.

GIMENES, C, I. Ocupar e resistir: entre o político e o pedagógico nas escolas ocupadas. Blog da Boitempo. São Paulo, 02 nov. 2016. Disponível em: $<$ https://blogdaboitempo. com.br/2016/11/02/ocupar-e-resistir-entre-o-politico-e-o-pedagogico-nas-escolas-ocupadas/>. Acesso em: 25 fev. 2017.

GOHN, M, G. Movimentos sociais e educação. São Paulo: Editora Cortez, 2012.

Movimentos sociais e lutas pela educação no Brasil: experiências e desafios na atualidade. In: XI ANPED SUL, 2016, Curitiba. Anais...Curitiba: Conferência de encerramento, 2016. p. 01-12.

. Movimentos sociais na contemporaneidade. Revista Brasileira de Educação, v.16, n. 47, p. 333-361, maio/ago. 2011.

GRAMSCl, A. Cadernos do Cárcere. v. 3. Rio de Janeiro: Civilização Brasileira, 2007.

LÊNIN, V, I. As tarefas revolucionárias da juventude. São Paulo: Expressão Popular, 2015.

LUXEMBURG, R. A revolução russa. Petrópolis: Vozes, 1991.

MARX, K. Sobre a questão judaica. São Paulo: Boitempo editorial, 2010.

MENDES JR, A. Movimento estudantil no Brasil. São Paulo: Editora Brasiliense, 1982.

MÉSZAROS, I. Educação para além do capital. São Paulo: Boitempo editorial, 2005.

Para além do capital. São Paulo: Boitempo editorial, 2002.

OCUPA PARANÁ. 2016. Nosso maior número foi. Disponível em: < http://ocupaparana. org/>. Acesso em: 28 fev. 2016.

ORTELLADO, P. A primeira flor de junho. In: CAMPOS, A, M; MEDEIROS, J; RIBEIRO, M, M. Escolas de lutas. São Paulo: Editora Veneta, 2016. p. 12-18.

PARREIRA, L, A; FILHO, M, J. A educação não formal: desafios de uma prática pedagógica. Serviço Social e Realidade, Franca, v. 19, n. 1, p. 241-267, 2010.

POERMER, A. J. O poder jovem: história da participação política dos estudantes brasileiros. Rio de Janeiro: Civilização Brasileira, 1979.

SANFELICE, J. L. Movimento estudantil: a UNE na resistência ao golpe de 64. São Paulo: Alínea, 2008.

SANTOS, J, S. Movimento de ocupação das escolas públicas paulista. In: II SEMINÁRIO NACIONAL DE TEORIA MARXISTA: O CAPITALISMO E SUAS CRISES, 2016, Uberlândia. Anais...Uberlândia, 2016.

SINGER, A.; LOUREIRO, I. As contradições do Lulismo: a que pontos chegamos? São Paulo: Boitempo, 2016. 
TONET, I. Atividades educativas emancipadoras. Práxis Educativa, Ponta Grossa, v. 9, n. 1, p. 09-23, 2014.

UNIÃO BRASILEIRA DOS ESTUDANTES SECUNDARISTAS. UBES divulga a lista das escolas ocupadas e pauta das mobilizações. 11 out. 2016. Disponível em: <http://ubes. org.br/2016/ubes-divulga-lista-de-escolas-ocupadas-e-pautas-das-mobilizacoes/>. Acesso em: 28. fev. 2016.

VALLE, M. R. 1968, o diálogo é a violência: movimento estudantil e ditadura militar no Brasil. Campinas: Editora Unicamp, 1999.

VÁZQUEZ, A, S. Filosofia da práxis. São Paulo: Expressão popular, 2011.

ZIBAS, D. M. L. A revolta dos pingüins e o novo pacto educacional chileno. Revista Brasileira de Educação, v.13, n. 38, p. 199-408, maio/ago. 2008.

ZINET, C. Centro de referências em educação integral. Escolas ocupadas mostram que outra educação é possível e necessária. 08 jun. 2016. Disponível em: < http://educacaointegral.org.br/reportagens/escolas-ocupadas-mostram-que-outra-educacao-e-possivel-e-necessaria/>. Acesso em: 02 mar. 2017.

Aldimara Catarina Delabona Brito Boutin: Doutoranda em Educação na Universidade Estadual de Ponta Grossa (UEPG). Mestre em Educação pela Universidade Estadual de Ponta Grossa (UEPG). Graduada em História pela Universidade Estadual de Ponta Grossa (UEPG). Membro do Grupo de Pesquisa Capital, Trabalho, Estado e Educação: Políticas Educacionais e Formação de Professores.

E-mail: audiboutin@hotmail.com

Simone de Fátima Flach: Graduada em Direito pela Universidade Estadual de Ponta Grossa e em Pedagogia pela Universidade Estadual de Ponta Grossa, mestre em Educação pela Universidade Federal do Paraná e doutora em Educação pela Universidade Federal de São Carlos (UFSCar). Docente na pós-graduação da Universidade Estadual de Ponta Grossa na área de Política Educacional.

E-mail:eflach@uol.com.br 